\title{
Establishment of epilepsy surgery in Peru
}

David A. Steven, MD, MPH, Carlos M. Vasquez, MD, Jose C. Delgado, MD, Willy Zapata-Luyo, MD, Alicia Becerra, MD, Elliot Barreto, MD, Miguel F. Arango, MD, and Jorge G. Burneo, MD, MSPH

Neurology ${ }^{\circledR}$ 2018;91:368-370. doi:10.1212/WNL.0000000000006029
Correspondence

Dr. Steven

david.steven@uwo.ca

\begin{abstract}
Epilepsy surgery is a well-established treatment for certain types of intractable epilepsy. While there is a relatively high number of epilepsy surgery centers in Canada and the United States, the same cannot be said about many other parts of the world, such as South America. Although there are notable exceptions, such as Brazil and Colombia, formal epilepsy surgery centers have been lacking in many South American countries, including Peru. Although sporadic cases have been performed in Peru, there was no formal epilepsy surgery center in the country as of 2011. Beginning in 2008, with the support of the Partnering Epilepsy Centers in America program of the North American Commission of the International League Against Epilepsy, the Epilepsy Program at Western University in London, Canada, was partnered with the Department of Epilepsy at the Instituto Nacional de Ciencias Neurologicas in Lima. This was the beginning of a long-term relationship that culminated in the establishment of the first 2 formal epilepsy surgery centers in Peru. The purpose of this communication is to briefly summarize the establishment of 2 independent epilepsy surgery programs in Peru and to document the methods with which this accomplishment was achieved.
\end{abstract}

From the Epilepsy Program, Department of Clinical Neurological Sciences (D.A.S., J.G.B.), and Department of Anesthesia (M.F.A.), Schulich School of Medicine and Dentistry, Western University, London, Canada; Department of Epilepsy (C.M.V., J.C.D., W.Z.-L.), Instituto Nacional de Ciencias Neurologicas; and Departments of Neurology (A.B.) and Neurosurgery (E.B.), Hospital Nacional Edgardo Rebagliati Martins, Lima, Peru.

Go to Neurology.org/N for full disclosures. Funding information and disclosures deemed relevant by the authors, if any, are provided at the end of the article. 


\section{Glossary}

ATL $=$ anterior temporal lobectomy; INCN = Instituto Nacional de Ciencias Neurologicas; PECA = Partnering Epilepsy Centers in America.

Epilepsy surgery is a well-established treatment for many types of intractable epilepsy, typically delivered within dedicated epilepsy surgery centers. While some countries have relatively large numbers of these centers, such facilities are lacking in others. This is particularly true in countries where financial limitations form a significant barrier.

Although sporadic epilepsy surgery cases such as lesionectomies had been performed prior to this project, there existed no dedicated epilepsy surgery center in Peru prior to 2011. We report the establishment of the first epilepsy surgery centers in Peru and describe the methods with which this was achieved.

\section{Methods}

Medical care in Peru is delivered via 3 systems: (1) the public system funded by the Ministry of Health (MINSA), (2) the social security system (EsSalud) funded mostly by employers, and (3) the private system. As the majority of advanced medical treatment occurs within the MINSA and EsSalud systems, we aimed to establish independent programs in these 2 systems.

At a basic level, establishing an epilepsy surgery program requires (1) specialized equipment such as video-EEG, MRI, and surgical equipment, (2) practitioners with specialized training, and (3) a collaborative interdisciplinary team involving neurology, neurosurgery, and neuropsychology. This program assisted with all 3 requirements.

Guidelines for epilepsy surgery were developed in line with those used in Canada; however, because of the lack of invasive EEG and advanced imaging techniques, cases were limited to those that did not require either of these modalities, such as straightforward temporal lobe epilepsy and lesion-related epilepsy.

\section{Results}

The project began at Instituto Nacional de Ciencias Neurologicas (INCN) in Lima, which is the national neurologic referral center for MINSA. In 2008, with support from the Partnering Epilepsy Centers in America (PECA) program of the North American Commission of the International League Against Epilepsy, the Epilepsy Program at Western University in London, Canada, was partnered with the Department of Epilepsy at INCN. ${ }^{1}$ That year, the Canadian team held workshops on epilepsy surgery in Lima and performed a needs assessment that revealed gaps in video-EEG capabilities and training in epileptology and epilepsy surgery. To address the former, lobbying by INCN neurologists led to the purchase of a videoEEG unit in 2009. Specialized training was addressed when
Dr. Jose Carlos Delgado (INCN neurologist) undertook training in epileptology in Canada and Brazil in 2009; Dr. Carlos Mao Vasquez (INCN neurosurgeon) became the first formally trained epilepsy surgeon in Peru after completing an epilepsy surgery fellowship in Mexico in 2010; and a neuropsychologist obtained specialized training in Mexico as well.

Having established video-EEG capabilities and acquiring the necessary training, INCN moved to start performing surgery. In 2011, to help prepare the INCN team for surgeries, a workshop was held in Lima on the presurgical evaluation of epilepsy surgery candidates. In addition, the joint Canadian/ Peruvian team held meetings with INCN administration to stress the importance of a collaborative interdepartmental approach to epilepsy surgery. Shortly thereafter, in September 2011 the team performed a lesionectomy for epilepsy, marking the beginning of the first epilepsy surgery program in Peru.

Ongoing interinstitutional dialogue continued and in 2012, the Canadian team returned to Peru to assist with the ongoing development of the program and to provide guidance for the first ever anterior temporal lobectomy (ATL) for epilepsy performed in Peru. Under the guidance of the Canadian team, Dr. Vasquez performed a left ATL on August 20, 2012. ${ }^{1,2}$ The procedure was successful and helped consolidate the confidence of the entire team. The INCN group has not looked back from this first case and as of December 2017 has performed 81 cases (table).

As stated above, it was important for the project to also develop capabilities in the EsSalud system. By 2013, some epilepsy surgery, mostly in children, was being performed at the EsSalud Hospital Nacional Guillermo Almenara in Lima. ${ }^{3}$ However, there remained no formal adult epilepsy surgery program with video-EEG in the EsSalud system. To this end, a similar collaboration was developed with the epilepsy team at the Hospital Nacional Eduardo Rebagliati Martins in Lima. Once again, the focus was on equipment, training, and

Table Epilepsy surgery cases performed at Instituto Nacional de Ciencias Neurologicas (INCN) and Rebagliati up to December 2017

\begin{tabular}{lll}
\hline Type & INCN & Rebagliati \\
\hline Temporal lobectomy & 56 & 9 \\
\hline Extratemporal resection & 8 & 0 \\
\hline Lesionectomy & 14 & 3 \\
\hline Others (callosotomy) & 3 & 0 \\
\hline Total & 81 & 12 \\
\hline
\end{tabular}


promoting interdisciplinary collaboration. Workshops on epilepsy surgery were held and specialized training was obtained for both neurosurgery and neurology. In 2012, Dr. Alicia Becerra, a neurosurgeon at Rebagliati, completed a fellowship in epilepsy surgery in London. After returning to Lima, Dr. Becerra performed the first ATL for epilepsy at Rebagliati in 2014. Subsequently, a close collaboration with the Department of Neurology developed, particularly with Dr. Elliot Barreto, who had previously undertaken an observership in Canada. This culminated in the establishment of the first video-EEG unit in the EsSalud system in 2016 and as of December 2017, 12 cases have been performed. The Canadian team returned in 2016, by which time both units were functioning independently. A Colombian Canadian neuroanesthetist joined the team to mentor the Peruvian anesthetists in awake craniotomy. Two awake surgeries with cortical mapping were performed; a dominant ATL at Rebagliati and a perirolandic cavernoma resection at INCN. The successful performance of these cases demonstrated how much progress has been made at these 2 centers from inception in 2011 to complex awake craniotomies in 2016.

\section{Discussion}

The first known cases of epilepsy surgery in Peru were reported by Rocca and Franco in 1955. ${ }^{4}$ They performed resections using corticography; however, the details and results were not presented. In 1973, Ortega and Gamero ${ }^{5}$ reported their experience treating generalized seizures with corpus callosotomy and anterior commisurotomy. Beyond these 2 reports, there was no record of any formal epilepsy surgery prior to 2011. Anecdotally, the Peruvian team confirmed that, with the exception of occasional lesionectomies, callosotomies, and one hemishperectomy in a child, there was no organized epilepsy surgery program as of 2011 .

It is important to emphasize that this intervention was meant as a transformative educational one, rather than a traditional medical mission style intervention. It was our belief that encouraging as much independence as possible was mandatory to generate confidence on the Peruvian side. Specifically, this meant that the Canadian neurosurgeon did not perform the surgeries, something that was crucial for the professional development of the now-independent Peruvian surgeons.

The next step will be to develop the capability to perform invasive EEG (iEEG). The main obstacle for this is financial. It is hoped that the success of these programs will develop administrative interest in providing resources for iEEG. Similarly, addition of neuromodulatory techniques and the integration of advanced diagnostic modalities such as PET or magnetoencephalography are future goals for these programs.

It is reasonable to question whether these 2 programs are an effective use of resources or whether they have a large enough effect on the care of epilepsy in general in Peru. With respect to the resources, the majority of the resources utilized were from outside of Peru. Those acquired with Peruvian resources, such as the video-EEG, have a minimal cost and are utilized for nonsurgical patients as well. In terms of overall effect, while these 2 programs directly affect only a small group of patients with epilepsy, it is hoped that these specialists will form the nucleus for the ongoing advancement of the overall care of patients with epilepsy in Peru and eventually train future generations of epilepsy specialists. Furthermore, it is hoped that these programs will increase the profile of epilepsy caregivers in Peru, which will hopefully assist in advocating for resources for measures that would have a broader public health effect, such as improved prevention of neurocysticercosis or increasing the availability of newer generation antiepileptic medications.

The success of these programs is strong evidence that with a dedicated, collaborative approach it is possible to initiate basic epilepsy surgery programs in countries with limited resources.

\section{Author contributions}

Dr. Steven: study concept and design, preparation of first draft of manuscript. Dr. Vasquez: study concept and design, critical revision of the manuscript for important intellectual content. Dr. Delgado: study concept and design, critical revision of the manuscript for important intellectual content. Dr. ZapataLuyo: study concept and design, critical revision of the manuscript for important intellectual content. Dr. Becerra: study concept and design, critical revision of the manuscript for important intellectual content. Dr. Barreto: study concept and design, critical revision of the manuscript for important intellectual content. Dr. Arango: study concept and design, critical revision of the manuscript for important intellectual content. Dr. Burneo: study concept and design, critical revision of the manuscript for important intellectual content.

\section{Study funding}

PECA Program of the North American Commission of the International League Against Epilepsy, Royal Bank of Canada, and Domino's Pizza of Canada.

\section{Disclosure}

D. Steven is receiving financial support from Livanova Canada for educational activities and is a consultant for the Renishaw Mayfield. C. Vasquez, J. Delgado, W. Zapata-Luyo, A. Becerra, E. Barreto, and M. Arango report no disclosures relevant to the manuscript. J. Burneo has received financial support from UCB Canada for research and educational activities. Go to Neurology.org/N for full disclosures.

\section{References}

1. Burneo JG, Delgado JC, Steven DA, et al. A collaborative effort to establish a com prehensive epilepsy program in Peru. Epilepsy Behav 2013;26:96-99.

2. Delgado JC, Vasquez CM, Zapata W, et al. Reporte del primer caso de lobectomía para el tratamiento de epilepsia refractaria de lóbulo temporal en el Perú. Rev Neuropsiquiatr 2017;80:151-154.

3. Mejía-Tupa MA, Pérez-Galdos P, Tori-Murgueytio A, Del Solar-Tafur M, AnicamaLima WE, Campos-Puebla MG. Cirugía de epilepsia en el Hospital Nacional Guillermo Almenara: primeros siete casos. Acta Med Per 2014;31:199-212.

4. Rocca ED, Franco P. La electrocorticografía en neurocirugía. Neurocirugía 1955;4:3-5.

5. Ortega VM, Gamero V. Anterior comissurotomy in the treatment for epilepsy. Excerpta Med 1973;293:20. 


\title{
Neurology
}

\author{
Establishment of epilepsy surgery in Peru \\ David A. Steven, Carlos M. Vasquez, Jose C. Delgado, et al. \\ Neurology 2018;91;368-370 \\ DOI 10.1212/WNL.0000000000006029
}

This information is current as of August 20, 2018

\section{Updated Information \& Services}

\section{References}

Subspecialty Collections

\section{Permissions \& Licensing}

\section{Reprints}

including high resolution figures, can be found at: http://n.neurology.org/content/91/8/368.full

This article cites 5 articles, 0 of which you can access for free at: http://n.neurology.org/content/91/8/368.full\#ref-list-1

This article, along with others on similar topics, appears in the following collection(s):

Access to care

http://n.neurology.org/cgi/collection/access_to_care All Epilepsy/Seizures

http://n.neurology.org/cgi/collection/all_epilepsy_seizures All global neurology

http://n.neurology.org/cgi/collection/all_global_neurology

Epilepsy surgery

http://n.neurology.org/cgi/collection/epilepsy_surgery_

Video/ EEG use in epilepsy

http://n.neurology.org/cgi/collection/video_eeg_use_in_epilepsy

Information about reproducing this article in parts (figures,tables) or in its entirety can be found online at:

http://www.neurology.org/about/about_the_journal\#permissions

Information about ordering reprints can be found online:

http://n.neurology.org/subscribers/advertise

Neurology ${ }^{\circledR}$ is the official journal of the American Academy of Neurology. Published continuously since 1951, it is now a weekly with 48 issues per year. Copyright @ 2018 American Academy of Neurology. All rights reserved. Print ISSN: 0028-3878. Online ISSN: 1526-632X.

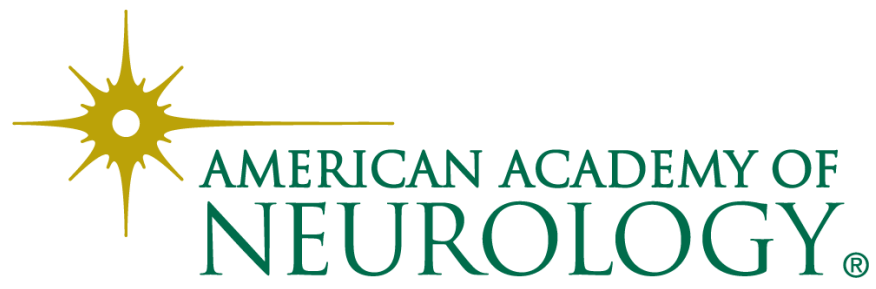

